\title{
Assessing the Efficiency of UPBJJ-UT Semarang Using Data Envelopment Analysis
}

\author{
Etty Puji Lestari
}

\begin{abstract}
Data Envelopment Analysis (DEA) is a relatively new data oriented approach for evaluating the performance of a set of peer entities called Decision Making Units (DMUs) which convert multiple inputs into multiple outputs. These DEA applications have used DMUs of various forms to evaluate the performance of entities, such as hospitals, universities, cities, courts, business firms, and others. The article is to analyze the Efficiency of Distance Learning Program Unit of the Open University (UPBJJ-UT) Semarang using Data Envelopment Analysis. Input variables used are the number of lecturer, number of students and tuition fee, while the output variable is the number of graduation. The results suggests that achievement performance of UPBJJ-UT Semarang is less efficient. This condition indicates inefficiency in production inputs such as lecturers and number of graduation as output. Therefore lecturers should be empowered to improve student graduation rates.
\end{abstract}

Index Terms-Efficiency, performance, data envelopment analysis, UPBJJ-UT semarang.

\section{INTRODUCTION}

Open University (Universitas Terbuka/UT) is one of the State Universities in Indonesia which was launched on 4 September 1984, pursuant to Decree of the President of the Republic of Indonesia No. 41 of 1984 (www.ut.ac.id). UT was established with the objectives : to provide expansive opportunity for Indonesian citizens and foreigners, wherever their place of residence, to attain higher education; to provide higher education services for those who, because of their work or due to other reasons, are not able to further their studies in face-to-face prominent higher education institutions and to develop academic and professional programs so far unaddressed by other universities that meet the genuine needs of national development.

In conducting education programs, UT cooperate with all state universities and a number of private universities as well as with relevant government agencies in Indonesia. In every province or regency/municipality where there are state universities, UT provides its services called the UPBJJ-UT (Distance Learning Program Unit of the Open University). UPBJJ is UT's regional technical executive units. The UPBJJ-UT functions as students' forum for academic administration as well as academic activities. It's task to provide day to day distance learning services.

The main functions of the UPBJJ-UT in carrying out those duties are: first, to conduct administrational, public relations and promotional activities under the coordination of the Head

Manuscript received February 20, 2014; revised April 22, 2014.

Etty Puji Lestari is with the Departement of Economics, Open University of Indonesia, Pondok Cabe, Jakarta 15418, Indonesia (e-mail: ettypl@ut.ac.id). of the Sub-Department of Administrations. The duties include providing academic administration and testing activities. These are not performed simultaneously but are interrelated and ongoing activities. Consequently one coordinator suffices to oversee all the activities. When the UPBJJ-UT's work load increases, the UPBJJ-UT can appoint another coordinator, one for registration and one for testing ; second, to provide learning support and learning material services which includes conducting tutorials, co-curricular and extracurricular activities. Tutorials in the future are expected to increase with the implementation of a new policy on specially-designed tutorials which will only need to be supervised by one coordinator; and finnally, to develop, foster and carry out cooperation with various institutions. This authority is in the hands of the Head of the UPBJJ-UT which would be rendered ineffective if delegated to another coordinator or staff.

UPBJJ-UT Semarang is one of regional technical executive units of Universitas Terbuka. As one of the largest unit, UPBJJ UT Semarang prosecuted should has optimal performance. Until now the assessment of performance in UPBJJ UT Semarang particular both internally and externally has not been done. Indicators used to assess performance such as implementation of routine job, administration services, provision of teaching materials, tutorials, and social activities, whether performed individually or programmed together with other units. Based on the background, the article aims to measure the performance of UPBJJ UT Semarang with different approach, using Data Envelopment Analysis (DEA).

DEA used in efficiency analysis commonly. Sutawijaya dan Lestari (2009) [1] conducted a study on the efficiency of banks in Indonesia. The result is the efficiency of government's banks more efficient than private and foreign banks. DEA can also be used to assess education as practiced by Hasanudin (2007) [2]. The research results that the efficiency at high schools in three districts (Brebes and Tegal city) were influenced by inputs such as teacher, salaries and computers.

\section{DATA ENVELOPMENT ANALYSIS}

DEA is a linear programming technique developed in the work of Charnes, et al. [3]. It is a non-parametric technique used in the estimation of production functions and has been used extensively to estimate measures of technical efficiency in a range of industries [4]. Like the stochastic production frontiers, DEA estimates the maximum potential output for a given set of inputs, and has primarily been used in the estimation of efficiency. However, again like the SPF approach, DEA also can be used to estimate capacity utilization [5]. The Färe, Grosskpof and Lovell approach, 
however, seeks to determine capacity output, conditional on the fixed input binding production. This is the weak concept of capacity output offered by Coelli et al. (2001) [6]. The strong concept includes the weak concept, while the weak concept does not include the strong concept of capacity output. In addition, the weak concept avoids problems caused by particular functional forms and decreasing returns to scale (e.g. the Cobb-Douglas production function, which does not have an absolute mathematical maximum).

DEA is receiving increasing importance as a tool for evaluating and improving the performance of manufacturing and service operations. It has been extensively applied in performance evaluation and benchmarking of schools, hospitals, bank branches, production plants, etc. (Charnes et al., 1994) [7]. This paper provides an introduction to DEA and some important methodological extensions that have improved its effectiveness as a productivity analysis tool. DEA is a multi-factor productivity analysis model for measuring the relative efficiencies of a homogenous set of decision making units (DMUs) (Talluri, 2000) [8]. The efficiency score in the presence of multiple input and output factors is defined as:

$$
\text { Effiiciency }=\frac{\text { weig hted sum of out puts }}{\text { weigted sum of inputs }}
$$

Assuming that there are $\mathrm{n}$ DMUs, each with $\mathrm{m}$ inputs and $\mathrm{s}$ outputs, the relative efficiency score of a test DMU $p$ is obtained by solving the following model proposed by Charnes et al. (1978) [3]:

$$
\begin{aligned}
& \max \frac{\sum_{k=1}^{s} v_{k} y_{k p}}{\sum_{j=1}^{m} u_{j} x_{j p}} \\
& \text { s.t } \frac{\sum_{i=0}^{n} v_{k} y_{k i}}{\sum_{j=1}^{m} u_{j} x_{j i}} \leq 1 \forall i
\end{aligned}
$$

$V_{k}, u_{j} \geq 0 \forall i, j$

where

$k=1$ to $s, j=1$ to $m, i=1$ to $n, y k i=$ amount of output $\mathrm{k}$ produced by (the number of graduation) DMU i, xji = amount of input $j$ utilized by DMU i, (number of lecturer, tuition fee and number of student)

$V k=$ weight given to output $\mathrm{k}, U j=$ weight given to input $j$.

The fractional program shown as 2) can be converted to a linear program as shown in 3). For more details on model development see Charnes et al. (1978) [3]. The above problem is run $n$ times in identifying the relative efficiency scores of all the DMUs. Each DMU selects input and output weights that maximize its efficiency score. In general, a DMU is considered to be efficient if it obtains a score of 1 and a score of less than 1 implies that it is inefficient. The variables which used in Data Envelopment Analysis methods consists of input and output. Input in this study consisted of the number of lecturers in UPBJJ-UT Semarang, number of students and tuition fees. The output is the number of graduation. The study period was from 2008 to 2012 .

\section{A. CRS and VRS Frontiers}

The envelopment surface will differ depending on the scale assumptions that underpin the model. Two scale assumptions are generally employed: constant returns to scale (CRS), and variable returns to scale (VRS). The latter encompasses both increasing and decreasing returns to scale. CRS reflects the fact that output will change by the same proportion as inputs are changed (e.g. a doubling of all inputs will double output); VRS reflects the fact that production technology may exhibit increasing, constant and decreasing returns to scale. As demonstrated in Section 2.6, input- and output-based capacity measures are only equivalent under the assumption of constant returns to scale (Pascoe, et al., 2003). However, there are generally a priori reasons to assume that fishing would be subject to variable returns and, in particular, decreasing returns to scale. Cooper, Seiford and Tone (2000) provide a discussion of methods for determining returns to scale. In essence, the researcher examines the technical efficiency given different returns to scale, and determines whether or not the observed levels are along the frontier corresponding to a particular returns to scale.

The effect of the scale assumption on the measure of capacity utilization is demonstrated in Fig. 1. Four data points (A, B, C, and D) are used to estimate the efficient frontier and the level of capacity utilization under both scale assumptions. Note that only fixed inputs are considered in Fig. 1. The frontier defines the full capacity output given the level of fixed inputs. With constant returns to scale, the frontier is defined by point $\mathrm{C}$ for all points along the frontier, with all other points falling below the frontier (hence indicating capacity underutilization). With variable returns to scale, the frontier is defined by points A, C and D, and only point B lies below the frontier i.e. exhibits capacity underutilization. The capacity output corresponding to variable returns to scale is lower than the capacity output corresponding to constant returns to scale (Pascoe, et al., 2003).

As with the SPF analysis, the measure of capacity utilization is estimated as the ratio of the actual output to the frontier level of output. With the exception of point $C$ (which has a capacity utilization of 100 percent under both assumptions), the measure of capacity utilization is lower (i.e. more underutilization) for each point when assuming constant returns to scale than when assuming variable returns to scale. Even for point $\mathrm{B}, O_{1} / O_{3}<O_{1} / O_{2}$.

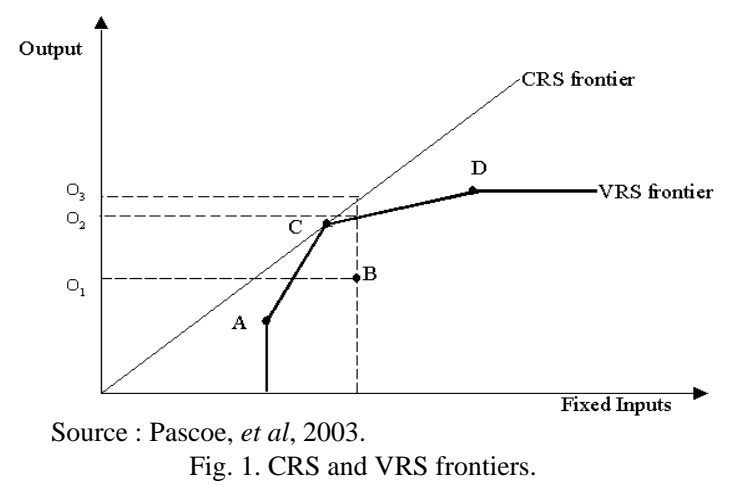

Hence, assuming a CRS frontier is likely to result in a greater estimate of capacity output and a lower estimate of capacity utilization than assuming a VRS frontier. As there are $a$ priori reasons for assuming variable returns to scale in fisheries it is recommended that the latter be used, and the results treated as lower bounds for capacity output and upper bounds for capacity utilization.

\section{B. Input and Output Orientations}

A range of DEA models have been developed that measure 
efficiency and capacity in different ways. These largely fall into the categories of being either input-oriented or output-oriented models. With input-oriented DEA, the linear programming model is configured so as to determine how much the input use of a firm could contract if used efficiently in order to achieve the same output level. For the measurement of capacity, the only variables used in the analysis are the fixed factors of production. As these cannot be reduced, the input-oriented DEA approach is less relevant in the estimation of capacity utilization. Modifications to the traditional input-oriented DEA model, however, could be done such that it would be possible to determine the reduction in the levels of the variable inputs conditional on fixed outputs and a desired output level.

\section{Performance Ranking in DEA}

Traditional DEA models do not allow for ranking DMUs, specifically the efficient ones. Also, it is possible in DEA that some of the inefficient DMUs are in fact better overall performers than certain efficient ones. This is because of the unrestricted weight flexibility problem in DEA. In the determination of relative efficiency, problem 3) allows for unrestricted factor weights (vk and uj). Thus, a DMU can achieve a high relative efficiency score by being involved in an unreasonable weight scheme (Dyson \& Thannassoulis, 1988; Wong \& Beasley, 1990). Such DMUs heavily weigh few favorable measures and completely ignore other inputs and outputs (Pascoe et al., 2003).

These DMUs can be considered as niche members and are not good overall performers. Cross-efficiencies in DEA is one method that could be utilized to identify good overall performers and effectively rank DMUs (Sexton et al., 1986). Cross-efficiency methods evaluate the performance of a DMU with respect to the optimal input and output weights (vk and uj) of other DMUs. The resulting evaluations can be aggregated in a cross efficiency matrix (CEM). In the CEM, the element in ith row and jth column represents the efficiency of DMU $\mathrm{j}$ when evaluated with respect to the optimal weights of DMU i. A DMU, which is a good overall performer, should have several high cross efficiency scores along its column in the CEM. On the other hand, a poorly performing DMU should have several low values. The column means can be computed to effectively differentiate between good and poor performers (Boussofiane et. al, 1991).

\section{RESULT AND DISCUSSION}

The results of calculations using ooutput maximisation radial model can be seen in Table I. The calculations shows that achievement of maximum efficiency is only found in 2008 and 2012. While the achievement of efficiency is not maximized in the year 2008 as many as 28.11 percent, the lowest compared to the achievement of efficiencies in 20010 and 2011.

Achievement of efficiency is less optimal because input is not used maximally. Efficiency calculation in 2008 claimed that the performance of UPBJJ-UT Semarang is less than the maximum. This can be seen from inefficiency of input production factors. The results of calculations for number of graduation has not reached 100 percent efficiency.
Targets set to achieve 100 percent efficiency is 7405 people, but realized only 2082 people, or just 28.1 percent. To achieve this it must be increased again in order to achieve maximum results. There are many strategies necessary to support maximum efficiency such as to improve the provision of learning support services to students, to maximize face to face tutorials, and to improve administration services.

TABLE I: CALCULATION DEA WITH OUTPUT MAXIMISATION
\begin{tabular}{|cc|}
\hline Year & Constan Return to Scale \\
\hline $\mathbf{2 0 0 8}$ & 28.11 \\
\hline $\mathbf{2 0 0 9}$ & 100.00 \\
\hline $\mathbf{2 0 1 0}$ & 57.37 \\
\hline $\mathbf{2 0 1 1}$ & 66.24 \\
\hline $\mathbf{2 0 1 2}$ & 100.00 \\
\hline
\end{tabular}

Sources: DEA calculation

TABLE II: TARGETS FOR UNIT Y 2008 EFFICIENCY 28.11\% RADIAL

\begin{tabular}{l|llll}
\hline Variable & Actual & Target & To Gain & Achieved \\
& & & & \\
\hline -Lecturer & 50.0 & 48.8 & $2.5 \%$ & $97.5 \%$ \\
-Student & 33642.0 & 33642.0 & $0.0 \%$ & $100.0 \%$ \\
-Tuition Fee & 20.0 & 19.5 & $2.5 \%$ & $97.5 \%$ \\
& & & & \\
+Graduate & 2082.0 & 7405.5 & $255.7 \%$ & $28.1 \%$ \\
\hline
\end{tabular}

The efficiency of variable lecturer is 97.5 percent, meaning that to get maximum efficiency; the performance must be increased by 2.5 percent. In actual, target to be achieved is 49 lecturers, but the real number of lecturer is 50 people so there is excess number of lecturers. Meanwhile, the value of the variable efficiency achieved student has reached the maximum value of 100 percent. Calculation efficiency for tuition fee is 97.5 percent, meaning that efficiency remains to be added 2.5 percent. Ideally, contributions of tuitiof fee is Rp 19.500, - per SKS, but the actual tuition fee is Rp 20,000, - per SKS. Efforts to improve the performance maximization UPBJJ-UT Semarang can be done with reference to the maximum performance in 2009 (see Table III). Technical efficiency in 2009 has reached 100 percent, indicate has maximum efficiency.

\begin{tabular}{l|ll}
\multicolumn{2}{c}{ TABLE III: PEER REFERENCE FOR EFFICIENCY UPBJJ UT 2008 } \\
\hline 2008 & & 2009 \\
\hline Actual & Lambda & 0.975 \\
& Scale & 1.000 \\
50.0 & -Lecturer & 50.0 \\
33642.0 & -Student & 34494.0 \\
20.0 & -Tuition Fee & 20.0 \\
2082.0 & +Graduate & 7593.0 \\
\hline
\end{tabular}

The results of efficiency using DEA CRS for 2010 achieved 57.4 percent. Inefficiencies present in variable number of lecturers, tuition fee and number of student. The lowest efficiency is tuition fee, which achieved 50,2 percent, indicate inefficiency 49,8 percent. Effort to increase the efficiency of performance in 2010 can refer in peers group in 2009. Basically there are three factors that lead to efficiency, ie when the same input generate greater output, with a smaller input produces the same output, and with a large input produces greater output. So although the orientation maximizing output, but the results of the DEA efficiency analysis method is also influenced by input level. 
TABLE IV: TARGETS FOR UNIT 2010 EFFICIENCY 57.4\% RADIAL

\begin{tabular}{lllll}
\hline Variable & Actual & Target & To Gain & Achieved \\
-Lecturer & 49.0 & 43.8 & $10.7 \%$ & $89.3 \%$ \\
-Student & 30201.0 & 30201.0 & $0.0 \%$ & $100.0 \%$ \\
-Tuition Fee & 20.0 & 17.5 & $12.4 \%$ & $87.6 \%$ \\
+Graduate & 3814.0 & 6648.0 & $74.3 \%$ & $57.4 \%$ \\
\hline
\end{tabular}

Achievement of the CRS DEA efficiency results with output maximization method showed that in 2011 the achievement of performance-based efficiency is 66.24 percent. Variables that have not reached the maximum efficiency are number of graduation and tuition fee. As well as inefficiency in the year 2010, the number of graduation is a variable that has the lowest efficiency value that is only 66.2 percent. Actually the number of students 68535 people, the number of graduation can be maximized to 7820 people in 2008, an increase of 51 percent compared to the actual conditions.

Efforts to improve the efficiency of performance in 2010 was done with reference to the performance of the ungrouped peer in 2009. Efficiency in 2009 was the maximum that is the whole input has been empowered to produce the maximum output (see Table V).

\begin{tabular}{l|ll}
\multicolumn{2}{l|}{ TABLE V: PEER REFERENCE FOR EFFICIENCY UPBJJ UT 2010 } \\
\hline 2010 & & 2009 \\
\hline Actual & Lambda & 0.876 \\
& Scale & 0.980 \\
49.0 & -Lecturer & 49.0 \\
30201.0 & -Student & 33804.1 \\
20.0 & -Tuition Fee & 19.6 \\
3814.0 & +Graduate & 7441.1 \\
\hline
\end{tabular}

Basically there are three factors that lead to efficiency; when the same inputs generate greater output, with a smaller input produces the same output, and with a large input produces greater output. So although the orientation maximizing output, but the results of the DEA efficiency analysis method is also influenced by input level.

\begin{tabular}{lllll}
\multicolumn{5}{c}{ TABLE VI: TARGETS FOR UNIT Y 2008 EFFICIENCY 66.24\% RADIAL } \\
\hline Variable & Actual & Target & To Gain & Achieved \\
& & & & \\
-Lecturer & 49.0 & 49.0 & $0.0 \%$ & $100.0 \%$ \\
-Student & 68535.0 & 68535.0 & $0.0 \%$ & $100.0 \%$ \\
-Tuition Fee & 20.0 & 19.9 & $0.5 \%$ & $99.5 \%$ \\
+Graduate & 5180.0 & 7820.0 & $51.0 \%$ & $66.2 \%$ \\
\hline
\end{tabular}

Achievement of the CRS DEA efficiency results with output maximization method showed that in 2008 the achievement of performance-based efficiency of 66.24 percent. The calculation of the efficiency of 2008 are shown in Table VI. Variables that have not reached the maximum efficiency is the number of graduation. As well as inefficiency in the year 2010, the number of graduation is a variable that has the lowest efficiency value that is only 66.2 percent. Actually the number of students 68.535 people, the number of graduation can be maximized to 7820 people in 2008, an increase of 51 percent compared to the actual conditions.

Another variable is the achievement of efficiency is less than 100 percent of the cost of education reached 99.5 percent This means that to achieve maximum efficiency of the performance must be increased by 0.5 percent. To improve efficiency, the performance of UPBJJ UT Semarang in 2008 should refer to the ungrouped peer in 2009 and 2012. The second-year level of efficiency has a maximum (see Table VII). Meanwhile, the achievement of efficiency targets in 2009 and 2012 has a maximum. This means that all resources are optimized to the maximum input to produce output.

\begin{tabular}{l|lll}
\multicolumn{3}{l|}{ TABLE VII: PEER REFERENCE FOR EFFICIENCY UPBJJ UT 2011 } \\
\hline Y 2011 & & Y 2009 & Y 2012 \\
\hline Actual & Lambda & 0.228 & 0.767 \\
& Scale & 0.980 & 1.000 \\
49.0 & -Lecturer & 49.0 & 49.0 \\
68535.0 & -Student & 33804.1 & 79078.0 \\
20.0 & -Tuition Fee & 19.6 & 20.0 \\
5180.0 & +Graduate & 7441.1 & 7935.0 \\
\hline
\end{tabular}

The most calculation using DEA states that there are much inefficiency in the variable number of graduation and number of lecturer. With the great number of students, UPBJJ- UT Semarang could increase the number of graduation. Many strategies can be done to improve performance, among others:

\section{1) Improve the quality of the tutorial}

To ensure the quality tutorials that does things UPBJJ Semarang as follows: first, increasing the tutor debriefing program. It contains a refresher briefing tutor, made beginning of each semester ahead of the tutorial. Tutor briefing materials include: systems of distance learning, tutorial guidance, concept maps, planning tutorial, tutorials execution, delivery and assessment of assignments, tutorial development, manufacturing RAT (draft tutorial program) and SAT (tutorial program unit), form a list of student attendance, form tutorial recap, recap the tutorial form, the results of evaluations last semester. Second, increase monitoring tutorial. Monitoring was conducted by the educational staff, equipped with a questionnaire on the performance evaluation of tutors and tutorial facilities and places.

Questionnaire about the performance of tutors who gathered were submitted to the coordinator BBLBA questionnaire about facilities and infrastructure to subag $\mathrm{Ka}$ TU to be analyzed. The results of the analysis of each questionnaire were followed up for improvement in the next semester. For example, to improve the quality tutor, from the results of analysis of monitoring tutorial, the tutor who has a scale of less than 3 were included briefing tutor. In addition UPBJJ Semarang prepare tutors who meet the requirements and further provided through courses with expertise in providing tutorial, which models the tutorial, compile RAT (Tutorial Activity Plan) and SAT (Unit Event Tutorial). This expertise will be useful when the tutor face to face with students.

\section{2) Improve the quality of lecturers}

Efforts to improve the performance of UPBJJ UT Semarang can be done include: first, encouraging teachers to gain knowledge in accordance with his fields. Second, teachers should also follow the training, both, from Open University of Indonesia and other institutions to improve their knowledge. Third, tutor improve their skills by doing a tutorial. 


\section{CONCLUSION}

The results of DEA calculation with constant returns to scale by using maximization of output shows that the achievement of maximum efficiency is only found in 2009 and 2012. While the achievement of the lowest efficiency was in 2008 that as many as 28.11 percent, lower than the achievement of efficiencies in 2010 and 2011. Achievement of maximum efficiency is not due to the input is not used to its full potential. Efficiency calculation in 2008 claimed that the performance of Semarang in years UPBJJ UT is less than the maximum. This can be seen from the less efficient use of input factors of production. In contrast to the efficiency calculation using the input minimization method calculated using the method of maximization of output variables that have not shown that the maximum yield is the number of graduation, number of lecturer and educational expenses.

Basically in the production process there are three factors that lead to efficiency, ie when the same input produces greater output with less input produces the same output, and with a large input produces greater output. So although the orientation maximizing output, but the results of the DEA efficiency analysis method is also influenced by input level. In conclusion, in the production process there are three factors that lead to efficiency, ie when the same input produces greater output with less input produces the same output, and with a large input produces greater output. Therefore, maximizing the use of the method is also influenced by input level.

\section{REFERENCES}

[1] A. Sutawijaya and E. P. Lestari, "The technical efficiency of indonesian banking post-crisis economy: An empirical study of application of DEA models," Journal of Development Economics, vol. 10, no. 1, pp. 49-67, June 2009.

[2] M. Hasanuddin, "Efficiency Measurement High School (SMA) in the Brebes district, Tegal, Period 2001-2003," Ragam, vol. 7, no. 2, 2007.

[3] A. Charnes, W. W. Cooper, and E. Rhodes, "Measuring the efficiency of decision making units," European Journal of Operational Research, vol. 2, pp. 429-444, 1978.

[4] W. W. Cooper, L. M. Seiford, and K. Tone, Data Envelopment Analysis: A Comprehensive Text with Models, Applications, References and DEA-Solver, Springer, 2007.

[5] R. Fare, S. Grosskopf, and C. A. K. Lovell, Production Frontiers, Cambridge: Cambridge University Press, 1994.

[6] T. Coelli and G. T. Emili, and P. Sergio, "Capacity utilisation and profitability: A decomposition of short-run profit efficiency," International Journal of Production Economics, Elsevier, vol. 79, no. 3, pp. 261-278, October, 2002.

[7] A. Charnes, W. W. Cooper, A. Y. Lewin, and L. M. Seiford, Data Envelopment Analysis: Theory, Methodology, and Applications, Boston: Kluwer, 1994.

[8] S. Talluri, "Data envelopment analysis: Models and extensions," Decision Line, vol. 31, no. 3, pp. 8-11.

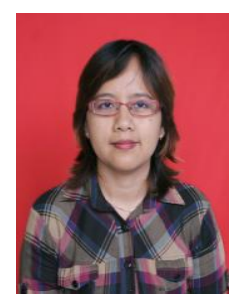

Etty Puji Lestari was born on Banyuwangi Indonesia on April 16th, 1974. She is a graduate from Islamic University Indonesia and received her doctorate in Economics from Diponegoro University, Indonesia. Now, she is a lecturer at Department of Economics and Master of Management in Open University of Indonesia (Universitas Terbuka) since 2002, where she taught econometrics, research methods and international economics. Her research interests in international economics, monetary and institutional economics. She is interested in linear and nonlinear models and Data Envelopment Analysis. Etty has published her research in international and national journal. She wrote many books not only economics books such as monetary economics, seminars research, cooperative economics, but also research-based books. Currently she is a member of Indonesian Economics Association and EABCN members (Euro Area Business Cycle Network). She also received an award as second best lecturers in her institution in 2012 . 